\title{
Phyllospheric plant growth promoting bacteria
}

\begin{abstract}
Bacteria which most abundantly colonize the phyllospheric region of plants are known as phyllobacteria. These bacteria are meant for variable plant-microbe interactions and are in direct contact with the environment so these have to adapt to the environmental extremes for their survival. Plant-microbe interactions in the phyllospheric regions are regulated by the substances secreted both by the bacteria as well as plants in addition to other factors. Among other metabolites are Indole-3-acetic acid (IAA) and glucosinolates that regulate plant-microbe interactions in the phyllospheric region in either positive or negative way. Bacterial Indole-3-acetic acid (IAA) is a secondary metabolite secreted by the phyllospheric bacteria that regulates physiology of plants by producing several desirable changes in plant body. The current study focuses on the phyllospheric bacteria and their interaction with the host plants.
\end{abstract}

Volume 5 Issue I - 2017

\author{
Shabana Wagi,' Ambreen Ahmed ${ }^{2}$ \\ 'Department of Botany, University of the Punjab, Pakistan \\ ${ }^{2}$ Quaid-e-Azam Campus, Pakistan
}

Correspondence: Ambreen Ahmed, Quaid-e-Azam Campus, Lahore 54590, Pakistan, Tel 00923334595 I0I,

Email ambreenahmedI@hotmail.com

Received: June 01, 2017 | Published: June 29, 2017

Keywords: phyllosphere, IAA, phyllobacteria, BID's, biostimulators

\section{Introduction}

Aerial parts of the plants that act as habitat for microorganisms are known as Phyllosphere. ${ }^{1}$ Phyllosphere is considered to be the largest and richest biological surface facilitating growth of several microorganisms like fungi, algae, archea, bacteria, protozoa and nematodes. ${ }^{2}$ Most common inhabitants of phyllosphere are bacteria which are known as phyllospheric bacteria or phyllobacteria. Both pathogenic and non-pathogenic bacteria usually reside in the phyllosphere. ${ }^{1}$ Phyllobacteria are epiphytes that colonize the plant leaves and face severe environmental fluctuations as compared to rhizospheric bacteria. UV- radiations, temperature and humidity regulates phyllospheric bacterial communities. ${ }^{3}$ There are various factors that define phyllospheric microbiota such as temperature, water, topology of the leaf surface, nutrient availability, age of leaves, plant species and leaf physiology. On the surface of the leaves, various morphological parts like trichomes, veins, cell wall junction of epidermis and stomata are the sites rich in microbial community since these regions protect bacteria from UV-radiations as well as other environmental extremes. Physico-chemical attributes that influence phyllospheric bacterial communities are not well understood yet. ${ }^{2}$ One of the most important feature of host-plant interactions is microbial production of plant hormones, which play positive part in the plant physiology for the benefits of microbes. ${ }^{4,5}$

\section{Interactions between plants and phyllospheric bacteria}

Bacterial colonization is strongly influenced by plant species. Dense population of bacteria is positively supported by the presence of some secondary metabolites like alkenyl glucosinolates 2-phenyl, 3-butenyl and 4-pentenyl while aromatic glucosinolate-2-phenylethyl produce negative influence on bacterial diversity in phyllosphere. Glucosinolates are also produced during plant-microbe interactions and act as defensive molecules against pathogenic bacteria. Structurally different aliphatic, aromatic and indole glucosinolates control specific pathogens. Negligible amount of this chemical is present in rhizosphere as compared to phyllosphere, however, excessive information is not present yet about the quatitative amount of glucosinolates that improves colonization of PGPB in phyllosphere. ${ }^{6}$
Plant-microbe interactions are regulated by bacterial genotype and ecological factors. All land and water plants grow in a friendly relationship with various kinds of microbiota and both get benefited from this relationship. Phyllospheric exudates and secondary metabolites are responsible for the colonization of these epiphytes or endophytes. These microbes not only maintain health of plants but also provide them protection and control microbial biodiversity. Phyllospheric microbiota especially play a vital defensive role in host plants, and improve their fitness and protect plants from environmental stress. Phyllospheric bacteria act as powerful antifungal, antibacterial and anticancer compounds because of the secretion of various secondary metabolites. ${ }^{7}$ Phyllospheric bacteria exchange resources with plants such as methanol produced during plant metabolism is used by methylobacterium which in turn provide plants with their auxin and nitrogen to overcome the deficiency of nitrogen and proper development of plants. ${ }^{8}$

Phyllospheric interactions are divided into three main categories i.e., positive, negative and neutral plant-microbe interactions. Some phyllospheric bacteria produce phytohormones and inhibit pathogens, hence positively influence plant growth. Phyllosphere of crops is extensively studied and it was observed that crop phyllospheric bacterial communities vary not only according to the plant species but also with varying cultivars. ${ }^{9}$

Indole-3-acetic acid (IAA) is one of the main auxin produced in plants which, regulates physiological processes of plants like cell division, cell elongation, phototactic movements and tissue differentiation etc. Bacterial IAA producers (BIP's) are the bacteria which interefere with the plant hormonal pool by addition of IAA either positively or negatively while bacterial IAA degraders (BID's) are the bacteria residing on the surface of the plants which, negatively affect the plant-microbe interactions. ${ }^{4}$ Phyllospheric bacteria help plants by acting as biostimulator, bio-protectants and biofertilizers. ${ }^{1,10}$

\section{Conclusion}

Phyllosphere is the region which usually comprises of the aerial parts of the plants specifically leaves. These bacteria may be epiphytes or endophytes. Plant-microbe relationships are regulated by both external morphological features of plants and bacterial secretion of 
secondary metabolites. Phyllobacteria face severe environmental fluctuations and thriving phyllospheric region is not an easy task. Phyllospheric bacteria help in plant growth promotion by adopting various strategies such as secreting various hormones, nitrogen fixation and by acting as antibacterial and anticancer agents. Thus, phyllospheric bacterial communities can be effectively used as biofertilizers and biostimulators.

\section{Acknowledgements}

None.

\section{Conflict of interest}

The author declares no conflict of interest.

\section{References}

1. Mazinani Z, Zamani M, Sardari S. Isolation and identification of phyllospheric bacteria possessing antimicrobial activity from Astragaulus Obtusifollius, Prosopis juliflora, Xanthium strumarium and Hippocrepis. Avicenna J Med Biotechnol. 2017;9(1):31-37.

2. Reisberg EE, Hildebrandt U, Riederer M, et al. Phyllosphere bacterial communities of trichome-bearing and trichomeless Arabidopsis thaliana leaves. Antonie Van Leeuwenhoek. 2012;101(3):551-560.

3. Prajapati RR, Jhala YK, Vyas RV. In vitro study of plant growth promoting methylotrophic bacterial consortium as a plant probiotics for paddy. Int J Curr Microbiol App Sci. 2017;6(5):2608-2626.
4. Leveau JHJ, Lindow SE. Utilization of plant hormone indole -3acetic acid for growth of pseudomonas putida strains 1290. Applied Environmental Microbiology. 2005;71(5):2365-2371.

5. Ahmed A, Hasnain S. Auxins as one of the factors of plant growth improvement by plant growth promoting rhizobacteria. Pol J Microbiol. 2014;63(3):261-266.

6. Schreiner M, Krumbein A, Ruppel S. Interaction between plant and bacteria: Glucosinolate and phyllospheric colonization of Cruciferous vegetables by Entrobact radicinicitans DSM 16656. $J$ Mol Microbiol Biotechnol. 2009;17(3):124-125.

7. Banik A, Kumar, U, Mukhopadhyay SK, et al. Dynamics of endophytic and epiphytic bacterial communities of Indian cultivated and wild rice (Oryza spp.) genotypes. Ecological Genetics and Genomics. 2017;3(5):7-17.

8. Cid FP, Inostroza NG, Graether SP, et al. Bacterial community structures and ice recrystallization inhibition activity of bacteria isolated from the phyllosphere of the Antarctic vascular plant Deschampsia Antarctica. Polar Biology. 2017;40(6):1319-1331.

9. Kim M, Singh D, Lai-Hoe A, et al. Distinctive phyllospheric bacterial communities in tropical trees. Microb Ecol. 2012;63(3):674-681.

10. Harsonowati W, Astuti RI, Wahyudi AT. Leaf blast disease reduction by rice-phyllosphere actinomycetes producing bioactive compounds. Journal of General Plant Pathology. 2017;83(2):98-108. 